\section{Redoks-svojstva ferocenom supstituiranih nukleobaza}

\author{
M. Toma* i V. Vrček \\ Sveučilište u Zagrebu Farmaceutsko-biokemijski fakultet, Ante Kovačića 1, 10000 Zagreb
}

https://doi.org/10.15255/KUI.2020.025

KUI-48/2020

Izvorni znanstveni rad

Prispjelo 21. travnja 2020.

Prihvaćeno 24. lipnja 2020.

\begin{abstract}
Sažetak
Pripravljena je serija ferocenom supstituiranih purinskih nukleobaza 1-10 te su izmjereni njihovi redoks-potencijali metodom cikličke voltametrije. Svi ispitani spojevi pokazali su reverzibilnu jednoelektronsku oksidaciju u rasponu potencijala od 330 do $470 \mathrm{mV}$. Također je uočena razlika redoks-potencijala od $100 \mathrm{mV}$ između N7 i N9 regioizomera ispitivanih nukleobaza. Ispitana je i acelularna aktivnost stvaranja reaktivnih kisikovih vrsta (ROS) kolorimetrijskom metodom s DCFH $\mathrm{s}_{2}$-DA te je utvrđeno da konjugati generiraju ROS, dok su ferocen i nukleobaze neaktivni. Različiti supstituenti na purinskom prstenu utječu na stvaranje ROS-a, što omogućuje dizajn biološki aktivnih konjugata ferocena i prikladnih nukleobaza.
\end{abstract}

Ključne riječi

Ferocenski konjugati nukleobaza, redoks-potencijal, reaktivne kisikove vrste (ROS)

\section{Uvod}

Organometalni derivati nukleobaza (OrDeN-i) nova su generacija konjugata u kojima su metaloceni povezani $\mathrm{s}$ temeljnim strukturnim elementima nasljeđivanja. ${ }^{1}$ Najpoznatiji metalocenski spoj, ferocen, karakteristične "sendvič" strukture u kojoj su dva ciklopentadienilna prstena koordinirana na $\mathrm{Fe}^{2+}$ (slika 1), intenzivno je istraživan još od njegova otkrića 1951.2,3 Ferocen je stabilan spoj, nije toksičan, biološki je inertan i elektrokemijski aktivan, pri čemu pokazuje reverzibilnu jednoelektronsku oksidaciju i služi kao unutarnji standard za elektrokemijska mjerenja $u$ organskim otapalima. ${ }^{3}$ Zahvaljujući lakoj funkcionalizaciji ugljikovih atoma na jednom ili oba ciklopentadienilna prstena, sintetiziran je velik broj ferocenskih konjugata koji sadrže organske ili anorganske fragmente pokrivajući tako različita područja znanstvenog istraživanja, od katalize, dizajna optičkih materijala i biosenzora do novih biološki aktivnih spojeva., ${ }^{3,4}$ nogi ferocenski konjugati pokazuju biološku aktivnost poput antitumorske, antibakterijske, antiparazitske i antifungalne. ${ }^{5}$ Osim što se uvodi u strukturu već poznatih lijekova, ferocen se konjugira i s nukleobazama kao biološki i farmakološki značajnim molekulama s ciljem sinteze biokonjugata koji će pokazati poboljšanu biološku aktivnost i poslužiti u medicinskoj i farmaceutskoj kemiji za razvoj novih terapeutskih agenasa. ${ }^{1}$ Poznato je da nukleobaze u DNA i RNA uzvojnicama formiraju parove baza preko vodikove veze, $\pi-\pi$ interakcija te hidrofobnih interakcija, pa se zbog navedene samoorganizirajuće prirode nukleobaza i elektrokemijske aktivnosti ferocena, ferocenski biokonjugati istražuju u supramolekulskoj kemiji i kemiji materijala te u bioanalitičkoj kemiji kao biosenzori. Zanimljiv je i podatak da vertikalna udaljenost između dva ciklopentadienilna prstena u ferocenu iznosi $0,35 \mathrm{~nm}$, što je vrlo slično vertikalnoj udaljenosti između centra dva susjedna para baza u DNA uzvojnici $(0,34 \mathrm{~nm})$. Očekivano, sintetizirani mono- $\mathrm{i}$ bis- derivati ferocena $\mathrm{i}$ nukleobaza samoorganiziraju se u Watson-Crick i obratne Watson-Crick parove čineći dvodimenzionalnu uzvojnicu. ${ }^{6}$

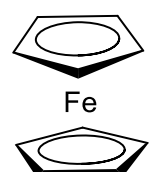

Slika 1 - Ferocen

Fig. 1 - Ferrocene

Upravo su navedena svojstva ferocena i njegovih derivata dovela do eksplozivnog razvoja bioorganometalne kemije i sve većeg interesa za sintezom ferocenskih biokonjugata kao kandidata za lijekove. Ferocenski derivati, zahvaljujući redoks-aktivnosti, pokazuju sposobnost generiranja reaktivnih kisikovih vrsta $(\mathrm{ROS})$, hidroksilnih radikala $\left({ }^{\circ} \mathrm{OH}\right)$ nastalih Fentonovom reakcijom, što se smatra osnovnim mehanizmom njihove antitumorske aktivnosti. ${ }^{5}$ Djelovanjem hidroksilnih radikala u stanicama dolazi do oksidativnog stresa i oštećenja stanica te, posljedično, stanične smrti. Osim toga, antitumorska aktivnost

\footnotetext{
*Autor za dopisivanje: Mateja Toma, mag. appl. chem.

e-pošta: mtoma@pharma.hr
} 
ferocenskih soli posljedica je toksičnosti ferocenskog kationa, pa bi ferocenski derivati mogli služiti kao prolijekovi koji bi se u organizmu oksidirali i prevodili u toksičan kationski kompleks. Hidroksilni radikali pojačavaju citotoksični učinak, pa je ferocenski motiv vrlo atraktivan u dizajnu antitumorskih agenasa koji će lako ući u stanicu i kontrolirati redoks-procese u njoj. ${ }^{7}$ Kao što je rečeno, ferocen se uvodi u strukturu već poznatih lijekova, a sintetizirani se derivati testiraju kao kandidati za lijekove za različita medicinska stanja. Uvođenjem ferocena u strukturu klorokina nastao je kandidat za antimalarik, ferokin (slika 2a), a zamjenom jedne fenilne skupine $s$ ferocenomu tamoksifenu pripravljen je potencijalni antitumorski lijek ferocifen (slika 2b). Ipak, prvi ferocenski lijek bio je feroceron (slika 3.) odobren 1971. godine u tadašnjem SSSR-u koji se upotrebljavao za liječenje deficijencije željeza, no na tržištu više nije dostupan. ${ }^{5}$ Ferokin, ferocenski derivat klorokina, u drugoj je fazi kliničkih ispitivanja kao antimalarik a, zahvaljujući redoks-aktivnosti ferocenskog dijela molekule $\mathrm{i}$ sposobnosti generiranja hidroksilnih radikala, pokazuje pozitivni učinak protiv klorokin-rezistentnih Plasmodium falciparum vrta. ${ }^{8}$ Osim antimalarijske aktivnosti, ferokin u kombinaciji s nekim kemoterapeuticima pokazuje poboljšanje antitumorske aktivnosti. ${ }^{9}$ Ferocifen je ferocenski analog tamoksifena, primarnog kemoterapeutika za hormonskiovisni (estrogen-receptor $\alpha$-pozitivni, $E R \alpha+$ ) rak dojke. Tamoksifen djeluje tako što se u organizmu oksidira u hidroksitamoksifen i veže za vezno mjesto na estrogen receptor, pa je djelotvoran samo za ER+ tumor. Ferocifen je, osim za $E R \alpha+$, aktivan i za ER $\alpha-$, hormonski neovisan rak dojke, što se također pripisuje redoks-aktivnosti ferocenskog dijela molekule, visoko je selektivan prema stanicama raka, a in vivo generira ROS. ${ }^{5,10}$ Upravo su navedene sintetizirane molekule ukazale na važnost ferocenske podjedinice kao bioizostera, za razliku od drugih sličnih organometalnih spojeva poput rutenocena $(\mathrm{Ru})$ ili cimantrena $(\mathrm{Mn})$, gdje zbog različitosti u elektronskoj strukturi i aktivnosti spomenuta poboljšana biološka aktivnost pripravljenih derivata izostaje..$^{5,11}$

Nukleobaze su jedna od zanimljivih meta za derivatizaciju ferocenom. Nukleozidi i analozi nukleobaza važna su klasa kemoterapeutskih agenasa među kojima se posebno ističu 5-fluorouracil i gemcitabin kao vodeći lijekovi na tržištu. Osim navedenih, poznati su citostatici i kemoterapeutski agensi 6-merkaptopurin, 6-tiogvanin i fludarabin, a spojevi azidotimidin (zidovudin), aciklovir, penciklovir i ganciklovir upotrebljavaju se kao antivirusni lijekovi. ${ }^{12}$ Brojne publikacije opisuju sintezu i (elektrokemijsku) karakterizaciju ferocenskih derivata nukleobaza, ${ }^{1}$ a provedena biološka ispitivanja pokazuju njihovu citotoksičnost za različite tumorske stanice, ${ }^{13-16}$ antiparazitsku i antitripanosomsku ${ }^{17}$ ili antibakterijsku aktivnost, ${ }^{14}$ kao i generiranje ROS vrsta. ${ }^{18}$ Tako primjerice, sintetizirani $\mathrm{N} 1$-ferocenilmetil timinski derivat pokazuje aktivnost prema adenokarcinomu dojke i dobar sinergijski učinak s ciklofosfamidom prema Lewisovom karcinomu pluća in vivo, ${ }^{13}$ a derivat ferocena i timina s nezasićenim mostom pokazuje dobru antitumorsku aktivnost in vitro na MCF-7 staničnim linijama s niskom vrijednošću $\mathrm{IC}_{50} \mathrm{u}$ odnosu na cisplatin. ${ }^{14}$
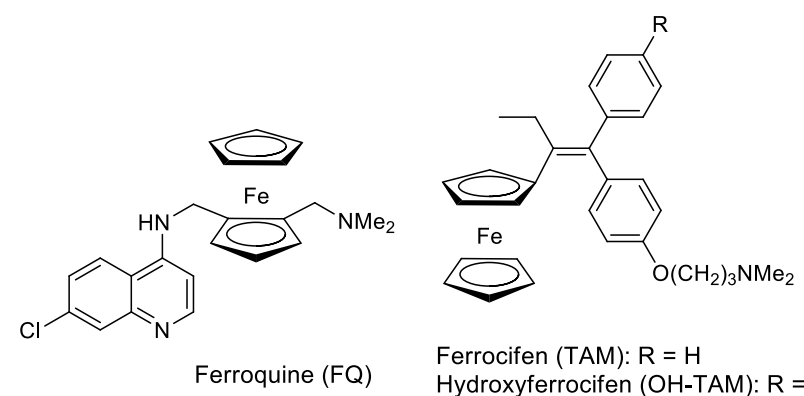

Ferrocifen (TAM): $\mathrm{R}=\mathrm{H}$ Hydroxyferrocifen $(\mathrm{OH}-\mathrm{TAM}): \mathrm{R}=\mathrm{OH}$

Slika 2 - a) Ferokin, potencijalni antimalarik, b) ferocifen, potencijalni antitumorski lijek

Fig. 2 - a) Ferroquine, potential antimalarial drug, b) ferrocifene, potential antitumor agent

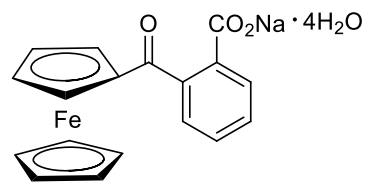

Ferrocerone

Slika 3 - Feroceron, prvi ferocenski lijek

Fig. 3 - Ferrocerone, first ferrocene drug

Razumijevanje utjecaja biomolekule konjugirane $\mathrm{s}$ ferocenom na elektrokemijska i biološka svojstva derivata od velike je važnosti u dizajnu novih molekula temeljenih na ferocenu. Osim što su kemijske modifikacije ferocenskog dijela biokonjugata ili same nukleobaze uzrok različitoj aktivnosti derivata, molekulski most (linker) koji spaja navedene dijelove molekule također može diktirati svojstva biokonjugata. Uz alkilne, metilenske i metinske poveznice, sintetizirani su i biokonjugati s karbonilnom skupinom u mostu koji oponašaju prirodne nukleozide gdje je šećerna komponenta zamijenjena ferocenom i preko amidne veze vezana na nukleobazu (shema 1a). ${ }^{19,20}$ U nastavku istraživanja ferocenskih derivata nukleobaza u ovom su radu ispitana redoks-svojstva nekoliko sintetiziranih ferocenoil-purinskih derivata (novosintetiziranih i ranije pripravljenih) kao i njihovo generiranje reaktivnih kisikovih vrsta izvan stanica, acelularno. Određivanje redoks-aktivnosti ferocenskih derivata nukleobaza izvan stanica omogućava predviđanje efekta biološke aktivnosti u stanicama i usmjerava dizajn molekula u željenom smjeru. 


\section{Eksperimentalni dio}

\subsection{Opće informacije}

Sva rabljena otapala sušena su i pročišćena prema preporučenom postupku sušenja agensima i/ili destiliranjem preko molekulskih sita veličine $3 \AA$. Za elektrokemijska mjerenja upotrijebljen je diklormetan HPLC čistoće pročišćen destilacijom iz kalcijeva hidrida. Tijek reakcije priprave praćen je tankoslojnom kromatografijom (TLC), na pločama 60F-254 presvučenim slojem silikagela Merck u odgovarajućem sustavu otapala. Za detekciju izoliranih komponenata upotrijebljena je UV-svjetlost valne duljine $254 \mathrm{~nm}$. Produkti su pročišćeni kromatografijom na koloni na silikagelu Fluka $(90 \AA$, $70-230$ mesh), pri čemu je kao eluens upotrijebljena smjesa diklormetan/aceton $\mathrm{u}$ odgovarajućem omjeru. Standardni ${ }^{1} \mathrm{H}$ i ${ }^{13} \mathrm{C}\{1 \mathrm{H}\}$ NMR spektri snimljeni su na spektrometru Varian INOVA 400, pri čemu uređaj radi na $399,6 \mathrm{MHz}\left({ }^{1} \mathrm{H}\right), \quad 375,9 \mathrm{MHz}\left({ }^{19} \mathrm{~F}\right)$ i $100,5 \mathrm{MHz}\left({ }^{13} \mathrm{C}\right)$. Uzorci su otopljeni u DMSO- $\mathrm{d}_{6}$ ili $\mathrm{CDCl}_{3}$ i mjereni pri $298 \mathrm{~K}$ u NMR cjevčici promjera $5 \mathrm{~mm}$. Kemijski pomaci (ס) $\mathrm{u}^{1} \mathrm{H}$ NMR spektrima izraženi su u jedinicama ppm u odnosu na tetrametilsilan (TMS, $\delta=0,0 \mathrm{ppm}$ ), a konstante sprege $(J)$ u hercima $(\mathrm{Hz})$. Pojedinačne rezonancije asignirane su na temelju njihovih kemijskih pomaka, intenziteta signala, multipliciteta signala i konstanti sprega $\mathrm{H}-\mathrm{H}$. FT-IR spektri snimljeni su u otopini diklormetana HPLC čistoće pomoću Bomem MB100 Mid FTIR spektrofotometra.

\subsection{Kemijska sinteza N7 i bis-N9-S6 ferocenoil-purinskih derivata}

Natrijev hidrid, $\mathrm{NaH}$ (36 mg, 1,5 mmol, 1,0 equiv), dodan je purinskoj bazi $(1,0 \mathrm{mmol}, 0,67$ equiv) suspendiranoj $\mathrm{u}$ $2 \mathrm{ml}$ DMF. Nakon miješanja na sobnoj temperaturi u argonskoj atmosferi 30 min bistroj otopini deprotonirane nukleobaze dodan je ferocenoil-klorid, FcCOCl (248,5 mg, 1,0 mmol, 1,0 equiv). Smjesa je miješana $15 \mathrm{~min}$, potom je neutralizirana s $1 \mathrm{mM} \mathrm{HCl}$ i ekstrahirana s diklormetanom. Organski sloj ispran je vodom, osušen s $\mathrm{Na}_{2} \mathrm{SO}_{4}$ i uparen na rotacijskom uparivaču. Reakcijska smjesa pročišćena je kolonskom kromatografijom u sustavu otapala diklormetan/aceton $=10: 0,5$ za spoj 2 te $7: 1$ za spoj 1 te su oba izolirana kao crvena praškasta krutina.

N7-Ferocenoil-purin (1): Crvena praškasta krutina, $m=57 \mathrm{mg}, \eta=42 \%(0,409 \mathrm{mmol}, 49,1 \mathrm{mg}$ purina $)$.

${ }^{1} \mathrm{H}$ NMR $\left(400 \mathrm{MHz}\right.$, DMSO-d $\left.6,25^{\circ} \mathrm{C}\right): \delta=9,45(\mathrm{~s}, 1 \mathrm{H}$, $\mathrm{C} 2-\mathrm{H}), 9,43$ (s, 1H, C6-H), 9,13 (s, 1H, C8-H), 5, 16 (s, 2H, $\mathrm{C} \alpha-\mathrm{H}), 4,83(\mathrm{~s}, 2 \mathrm{H}, \mathrm{C} \beta-\mathrm{H}), 4,38(\mathrm{~s}, 5 \mathrm{H}, \mathrm{Cp}-\mathrm{H}) \mathrm{ppm}$. ${ }^{13} \mathrm{C}\left\{{ }^{1} \mathrm{H}\right\} \quad \mathrm{NMR} \quad\left(100 \mathrm{MHz}, \mathrm{CDCl}_{3,}, 25^{\circ} \mathrm{C}\right): \quad \delta=169,2$ (FCCO), 160,9 (C4), 154,7 (C8), 148,8 (C6), 144,8 (C2), 124,6 (C5), 73,9 (C $\beta), 72,8$ i 72,1 (C $\alpha), 71,1(\mathrm{Cp})$, 70,0(Ci).
IR $\left(\mathrm{CH}_{2} \mathrm{Cl}_{2}\right) v_{\max } / \mathrm{cm}^{-1}=3075 \mathrm{i} 3028 \mathrm{j}(\mathrm{C}-\mathrm{H}$ ar. $\mathrm{i}=\mathrm{C}-\mathrm{H})$, $1692 \mathrm{j}(\mathrm{C}=\mathrm{O}), 1583 \mathrm{j}(-\mathrm{C}=\mathrm{N}), 1197 \mathrm{i} 1139 \mathrm{~s}(\mathrm{Ar}-\mathrm{C}-\mathrm{H})$.

Bis-ferocenoil-6-merkaptopurin (2): Crvena praškasta krutina, $m=34 \mathrm{mg}, \quad \eta=20 \% \quad(0,295 \mathrm{mmol}, 45 \mathrm{mg}$ merkaptopurina).

${ }^{1} \mathrm{H}$ NMR $\left(400 \mathrm{MHz}, \mathrm{CDCl}_{3}, 25^{\circ} \mathrm{C}\right): \delta=9,11(\mathrm{~s}, 1 \mathrm{H}, \mathrm{C} 8-\mathrm{H})$, $8,77(\mathrm{~s}, 1 \mathrm{H}, \mathrm{C} 2-\mathrm{H}), 5,12(\mathrm{~s}, 2 \mathrm{H}, \mathrm{C} \alpha-\mathrm{H}), 4,77(\mathrm{~s}, 2 \mathrm{H}, \mathrm{C} \beta-\mathrm{H})$, 4,46 (s, 5H, Cp-H), 5,01 (s, 2H, C $\alpha-\mathrm{H}), 4,63(\mathrm{~s}, 2 \mathrm{H}, \mathrm{C} \beta-\mathrm{H})$, $4,33(\mathrm{~s}, 5 \mathrm{H}, \mathrm{Cp}-\mathrm{H}) \mathrm{ppm} .{ }^{13} \mathrm{C}\left\{{ }^{1} \mathrm{H}\right\}$ NMR $\left(100 \mathrm{MHz}, \mathrm{CDCl}_{3}\right.$, $\left.25^{\circ} \mathrm{C}\right): \delta=187,1(\mathrm{FCCOS}), 168,6(\mathrm{FCCO}), 154,2$ (C2), 153,5 (C6), 150,6 (C4), 143,9 (C8), 136,6 (C5), 73,9 (С ), 72,8 i 72,6 (Co), 71,1 i 71,0 (Cp), 70,9 i 69,8 (Ci).

IR $\left(\mathrm{CH}_{2} \mathrm{Cl}_{2}\right) v_{\max } / \mathrm{Cm}^{-1}=3055$ i $2985 \mathrm{j}(\mathrm{C}-\mathrm{H}$ ar. $\mathrm{i}=\mathrm{C}-\mathrm{H})$, 2686 slaba $(\mathrm{S}-\mathrm{H}), 1690 \mathrm{j}(\mathrm{C}=\mathrm{O}), 1564 \mathrm{j}(-\mathrm{C}=\mathrm{N}), 1272 \mathrm{j}$ $(-\mathrm{C}=\mathrm{S}), 1185$ i 1130 š $(\mathrm{Ar}-\mathrm{C}-\mathrm{H}), 769$ š $(\mathrm{C}-\mathrm{S}$ ili $\mathrm{S}-\mathrm{H})$.

\subsection{Elektrokemijska mjerenja}

Elektrokemijska mjerenja provedena su metodom cikličke voltametrije (CV) i voltametrijom s pravokutnim izmjeničnim signalom pobude (SWV) u 1,0 mM otopini analita uz $\left[\mathrm{N}_{\mathrm{n}} \mathrm{Bu}_{4}\right]\left[\mathrm{B}\left(\mathrm{C}_{6} \mathrm{~F}_{5}\right)_{4}\right]$ kao elektrolit $\mathrm{u}$ suhom diklormetanu, na sobnoj temperaturi i argonskoj atmosferi. Mjerenje je provedeno na instrumentu Radiometer Voltalab PGZ 100 spojenom s osobnim računalom. Elektrokemijska ćelija sastoji se od tri elektrode, Pt protuelektrode, staklene ugljikove elektrode kao radne elektrode i referentne elektrode koja se sastoji od dva dijela. Unutarnja elektroda referentne elektrode je kapilara sa semipermeabilnom membranom $u$ kojoj se nalazi $\mathrm{Ag} \mathrm{Ag}^{+}\left(0,01 \mathrm{moll}^{-1} \quad \mathrm{AgNO}_{3}\right.$ u $\left.\mathrm{CH}_{3} \mathrm{CN}\right)$ i vodljiva sol $\left[\mathrm{N}_{n} \mathrm{Bu}_{4}\right]\left[\mathrm{B}\left(\mathrm{C}_{6} \mathrm{~F}_{5}\right)_{4}\right]$, a vanjska elektroda sadrži otopinu $0,1 \mathrm{M}$ $\left[\mathrm{N}_{n} \mathrm{Bu}_{4}\right]\left[\mathrm{B}\left(\mathrm{C}_{6} \mathrm{~F}_{5}\right)_{4}\right]$ u $\mathrm{CH}_{2} \mathrm{Cl}_{2}$. Radna elektroda je pripremljena poliranjem $\mathrm{s}$ dijamantnom pastom $1 \mathrm{~mm}$ i $4 \mathrm{~mm}$ na papiru za poliranje. U takvim su se uvjetima svi eksperimenti pokazali reproducibilnima u rasponu od $\pm 5 \mathrm{mV}$. Svi eksperimentalno dobiveni potencijali interno su referencirani u odnosu na $\mathrm{Ag} / \mathrm{Ag}^{+}$referentnu elektrodu, a svi prezentirani rezultati referencirani su u odnosu na ferocen, kako je preporučeno prema IUPAC-u. Referenciranje je provedeno dodavanjem vrijednosti $-614 \mathrm{mV}$ na eksperimentalno izmjerene podatke, pri čemu je dekametilferocen $\left(\mathrm{FC}^{*}\right)$ upotrijebljen kao interni standard (u korištenim eksperimentalnim uvjetima redokspotencijal $\mathrm{FC}^{*} / \mathrm{Fc}^{*+}$ je na $-614 \mathrm{mV}$ u odnosu na $\mathrm{FcH} / \mathrm{FcH}^{+}$ i $\Delta E_{\mathrm{p}}=60 \mathrm{mV}$, dok je ferocenski par $\mathrm{FcH} / \mathrm{FcH}^{+}$na $220 \mathrm{mV}$ $\mathrm{u}$ odnosu na $\mathrm{Ag} / \mathrm{Ag}^{+}$i $\Delta E_{\mathrm{p}}=61 \mathrm{mV}$ ). Konačno, za postavljanje formalnog redoks-potencijala para $\mathrm{FCH} / \mathrm{FCH}^{+}$ na $E^{\circ \prime}=0,0 \mathrm{mV}$ korišten je Microsoft Excel. ${ }^{21}$ 


\subsection{Mjerenje izvanstanične ROS aktivnosti}

Sposobnost generiranja reaktivnih kisikovih vrsta izvan stanica ispitana je spektrofotometrijskom metodom $\mathrm{s}$ $\mathrm{DCFH}_{2}$-DA. Pripravljene su otopine određenih koncentracija analita $\left(250 \mathrm{mgl}^{-1}, 125 \mathrm{mgl}^{-1}, 62,5 \mathrm{mgl}^{-1}\right.$, $31,3 \mathrm{mgl}^{-1}, 15,6 \mathrm{mgl}^{-1}, 7,8 \mathrm{mgl}^{-1}, 3,9 \mathrm{mgl}^{-1}$ ) u DMSO. Metoda se sastoji od mjerenja promjene intenziteta fluorescencije spoja $\mathrm{DCFH}_{2}$-DA, 2,7diklordihidrofluoresceina koji ne fluorescira, ali se u prisutnosti ROS vrsta oksidira u DCF, 2,7-diklorfluorescein i fluorescira. $1300 \mu \mathrm{l} 1 \mathrm{mM}$ otopine $\mathrm{DCFH}_{2}$-DA (pripravljene iz $10 \mathrm{mM}$ "stock" otopine) hidrolizirano je s $5,2 \mathrm{ml} 0,01 \mathrm{M} \mathrm{NaOH} 30$ min na sobnoj temperaturi u mraku. Hidroliza je zaustavljena s 19,5 ml 0,1 M PBS-a, a dobivena $50 \mu \mathrm{M}$ otopina razrijeđena je s otopinom 0,01 M PBS-a do koncentracije od $10 \mu \mathrm{M}$. Tako pripremljena fluorescentna boja dodana je pripravljenim koncentracijama analita na mikrotitarskoj pločici (96 "well plate"), a mjerenje je provedeno na instrumentu Victor microtitar plate reader Spectrometer, Perkin Elmer na valnim duljinama od $485 \mathrm{~nm}$ za ekscitaciju i $530 \mathrm{~nm}$ za emisiju, kroz 90 min. Provedeni su i testovi interferencija. Test autofluorescencije proveden je mjerenjem promjene intenziteta fluorescencije u PBS-u, a test gašenja fluorescencije s 0,1 $\mu \mathrm{M}$ otopinom F-DA (fluoresceina). ${ }^{22,23}$

\section{Rezultati i rasprava}

\subsection{Kemijska sinteza ferocenskih derivata nukleobaza}

U nastavku istraživanja na ferocenoil-supstituiranim nukleobazama (shema 1a, 3-10) ${ }^{20}$ pripravljena su dva nova purinska derivata, ferocenoil-purin (1) kao osnovni derivat te bis-ferocenoil-6-merkaptopurin (2), sumporni analog ferocenoil-purina, kao što je prikazano na shemi $1 \mathrm{~b}$. Reakcija je provedena u dva stupnja i u prvom koraku obuhvaća deprotoniranje nukleobaze, koja u drugom koraku reagira s ferocenoil-kloridom, pri čemu nastaje odgovarajući ferocenski kopulat. Tijekom aciliranja purinskih baza s ferocenoil-kloridom nastaju dva produkta, N7 i N9, s različitim udjelom u reakcijskoj smjesi, koji ovisi o C6-supstituentu ( $\mathrm{R}=\mathrm{Me}, \mathrm{NH}_{2}, \mathrm{OBz}, \mathrm{NHBz}$ ) (shema 1a). $\mathrm{U}$ reakciji purina s ferocenoil-kloridom također nastaju N7 i N9 regioizomeri, pri čemu je N7 većinski produkt (90\%). Formiranje obaju produkata tijekom reakcije aciliranja potvrđeno je praćenjem procesa in situ pomoću ${ }^{1} \mathrm{H}$ NMR spektroskopije, ali izoliran je samo jedan produkt asigniran kao N7. Različiti udjeli N7 i N9 produkata posljedica su supstitucijskih i elektronskih učinaka na C6 položaju purinskog prstena. Tako je N9 položaj dostupniji za aciliranje iz steričkih razloga te najčešće predstavlja termodinamički stabilniji produkt. Osim steričkih i elektronskih efekata, na omjer nastalih izomera mogu utjecati i reakcijski uvjeti poput izbora otapala i baze upotrijebljene za deprotoniranje. ${ }^{24}$ Međutim, u slučaju purina uočena je veća reaktivnost N7 položaja. Tako, na primjer, u reakciji s di-terc-butil-dikarbonatom kao većinski produkt aciliranja purina nastaje $\mathrm{N} 7$ produkt. ${ }^{25} \mathrm{U}$ reakciji ferocenoil-klorida i 6-merkaptopurina $u$ istim je reakcijskim uvjetima nastao bis-ferocenoilirani produkt, N9,C6-S-bis-ferocenoil-purin (shema 1b). Takav tijek reakcije je očekivan i literaturno je poznat nastanak $\mathrm{S}, \mathrm{N}$-disupstituiranih pirimidinskih nukleobaza. ${ }^{26} \mathrm{Za}$ takav je ishod odgovorna veća nukleofilnost sumpora od dušika koji se deprotonira kao i dušikov atom te dolazi do N9 i C6-S aciliranja merkaptopurina.
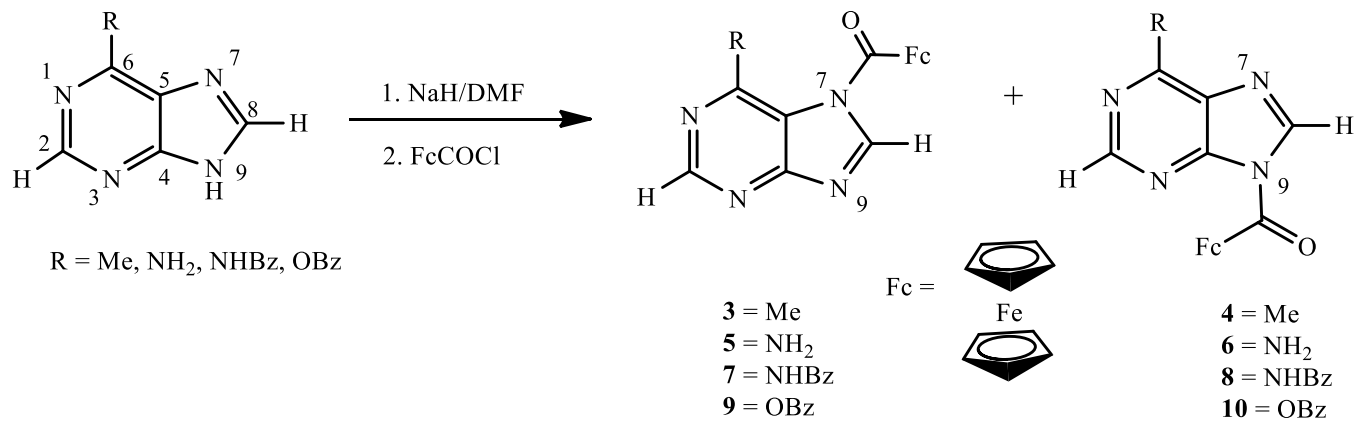

Shema 1a - Regioselektivna sinteza ferocenskih derivata različito supstituiranih purinskih nukleobaza

Scheme 1a - Regioselective synthesis of ferrocene derivatives with differently substituted purine nucleobases 
<smiles>c1ncc2nc[nH]c2n1</smiles><smiles></smiles>
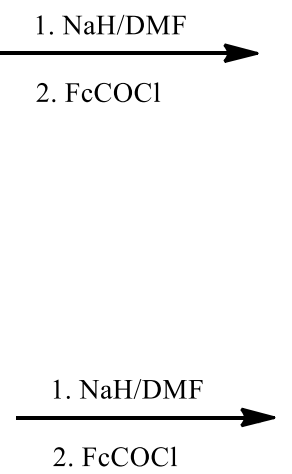<smiles>O=C(F)N1Nc2cncnc2N1</smiles><smiles></smiles>

2

Shema $1 b$ - Regiospecifična sinteza ferocenskih derivata purina i merkaptopurina

Scheme $1 b$ - Regiospecific synthesis of purine and mercaptopurine ferrocene derivatives

\subsection{Elektrokemijska mjerenja}

Elektrokemijska svojstva ferocenoil-purinskih derivata 1-10 ispitana su metodom cikličke voltametrije (CV) i voltametrijom $\mathrm{s}$ pravokutnim izmjeničnim signalom pobude (SWV) kako bi se odredio njihov redoks-potencijal. Mjerenja su provedena u $1,0 \mathrm{mM}$ otopini analita uz $\left[\mathrm{N}_{n} \mathrm{Bu}_{4}\right]\left[\mathrm{B}\left(\mathrm{C}_{6} \mathrm{~F}_{5}\right)_{4}\right]$ kao elektrolit u suhom diklormetanu, na sobnoj temperaturi i argonskoj atmosferi. Svi spojevi 1-10 pokazuju reverzibilnu jednoelektronsku oksidaciju koja odgovara oksidaciji i redukciji ferocenskog dijela molekule, a izmjereni su redokspotencijali $E^{\circ 1} \mathrm{u}$ rasponu 330 - $475 \mathrm{mV}$ što je, dakle, pozitivnije od redokspotencijala referentnog ferocenskog para $\mathrm{Fc} / \mathrm{FC}^{+}$. Stoga se ferocenski konjugati nukleobaza teže oksidiraju od samog ferocena za što bi mogla biti odgovorna karbonilna skupina u poveznici koja ima elektron odvlačeća svojstva. ${ }^{27}$ Kada se karbonilna skupinu u linkeru zamijeni s metilenskom skupinom kao u slučaju pirimidinskog kopulata ferocenilmetiltimina, redukcijski se potencijal pomiče u niže vrijednosti prema referentnom paru $\mathrm{Fc} / \mathrm{FC}^{+} .{ }^{28}$

Spojevi $4(\mathrm{R}=\mathrm{Me}), \mathbf{6}\left(\mathrm{R}=\mathrm{NH}_{2}\right), \mathbf{8}(\mathrm{R}=\mathrm{OBz})$ i $\mathbf{1 0}$ $(\mathrm{R}=\mathrm{NHBz})$ su N9-ferocenski derivati te pokazuju redoks-potencijale u rasponu od 330 do $355 \mathrm{mV}$, dok odgovarajući N7 regioizomeri 3, 5 i 7 pokazuju signale redukcijskih potencijala od 420 do $475 \mathrm{mV}$. Prema tome, N7 derivati se teže oksidiraju od N9 izomera, odnosno N7 derivati su bolji oksidansi. Svi navedeni redoks-procesi su reverzibilni i $\Delta E_{\mathrm{p}}$ iznosi $60-85 \mathrm{mV}$. Bis-N9,C6-S-diferocenoil supstituirani purinski derivat $\mathbf{2}$ pokazuje, umjesto očekivana dva, samo jedan reverzibilni proces za oba ferocenska prstena. Usporedbom krivulje redukcijskog potencijala spoja $\mathbf{2}$ dobivene metodom diferencijalne pulsne voltametrije (SWV - slika 4) i internog standarda dekametilferocena ( $\mathrm{FC}^{*}$, pri čemu su koncentracije analita i Fc* $1 \mathrm{mM}$ ) vidi se proširenje signala koje upućuje na postojanje dva gotovo istodobna procesa oksidacije i redukcije čiji su potencijali previše bliski da bi se jasno razlikovali. Suprotno, SWV voltamogram spoja $\mathbf{4}$ dobiven $\mathrm{u}$ istim uvjetima ukazuje na postojanje jednog procesa oksidacije i redukcije koji odgovara jednom ferocenu prisutnom u strukturi spoja 4. Redoks-potencijal spoja 2 iznosi 365 mV, a ciklički voltamogrami odabranih spojeva prikazani su na slici 5. Zanimljivo je da se na temelju vrijednosti redoks-potencijala mogu razlikovati N7 i N9 izomeri ferocenoil-purina. Stoga redoks-potencijali mogu poslužiti kao metoda identifikacije pojedinog izomera (koja je vrlo opsežna i zahtijeva kombinacije nekoliko spektroskopskih tehnika) budući da je redoks-potencijal N9 izomera uvijek niži u odnosu na N7. Prosječni redoks-potencijal N9 izomera iznosi približno $350 \mathrm{mV}$, dok za N7 izomere iznosi oko $450 \mathrm{mV}$. Redoks-potencijal ferocenoil-purinskog derivata $\mathbf{1}$ iznosi $450 \mathrm{mV}$, što odgovara N7 izomeru i dodatno podupire asigniranje tog spoja kao N7 izomera.

\subsection{Izvanstanična ROS aktivnost spojeva 1-10}

Ekstracelularna ROS aktivnost derivata 1-10 izmjerena je spektrofotometrijski pomoću $\mathrm{DCFH}_{2}$-DA. Mjerena je promjena intenziteta fluorescencije spoja 2,7-diklordihidrofluoresceina koji u diacetatnoj formi ne fluorescira, a nakon hidrolize $\mathrm{s} \mathrm{NaOH}$ do $\mathrm{DCFH}_{2}$, u prisutnosti ROS vrsta se oksidira u DCF 2,7-diklorfluorescein te fluorescira. Stoga je intenzitet fluorescencije proporcionalan količini nastalih ROS vrsta, odnosno sposobnosti spoja da generira kisikove radikale. Ekstracelularno određivanje ROS aktivnosti spoja može poslužiti kao preliminarni test ROS aktivnosti i kao temelj predviđanja aktivnosti unutar stanica. ${ }^{29}$ 


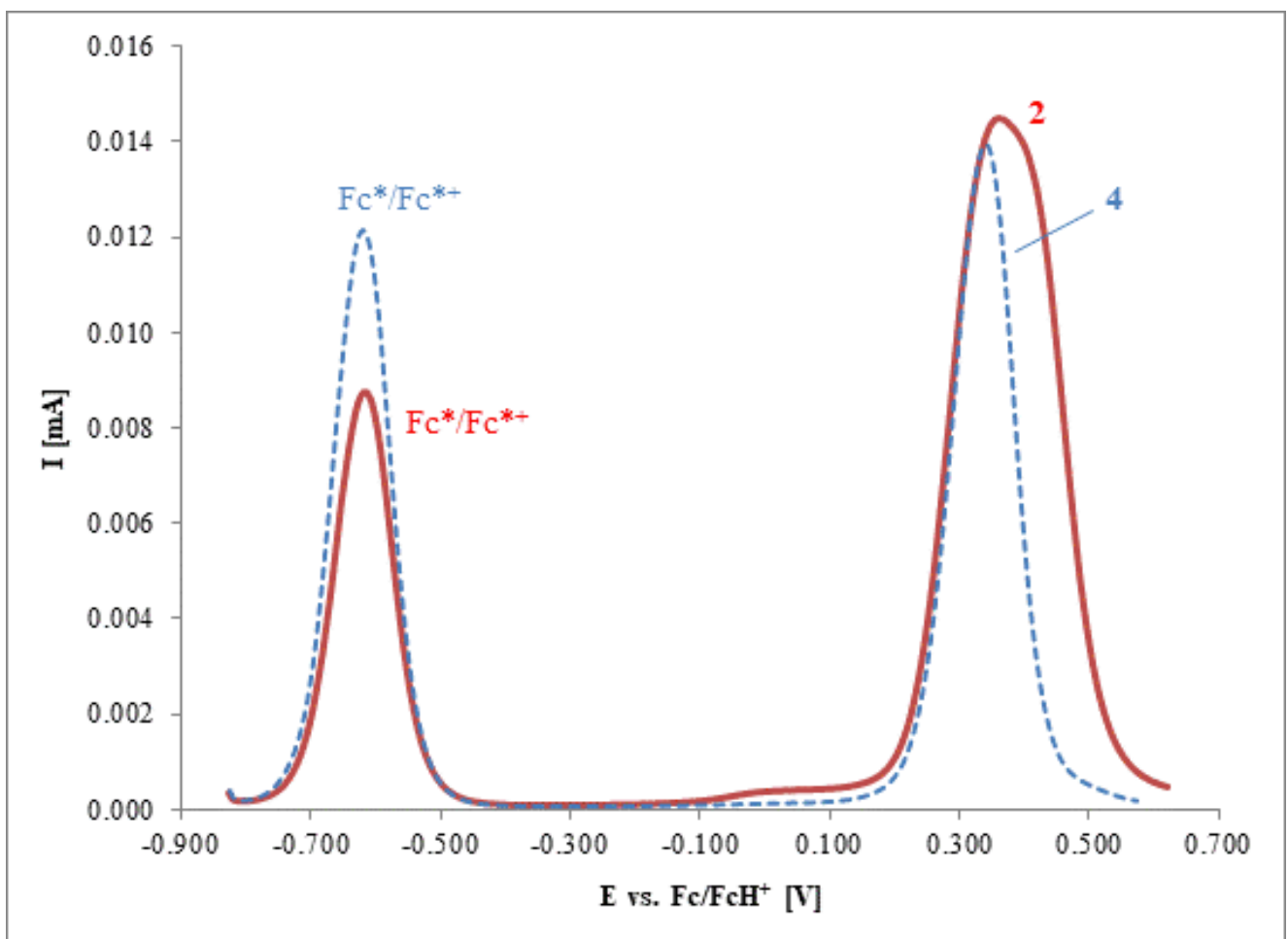

Slika 4 - SWV voltamogrami spojeva 2 i 4

Fig. 4 - SWV voltammograms of compounds $\mathbf{2}$ and $\mathbf{4}$

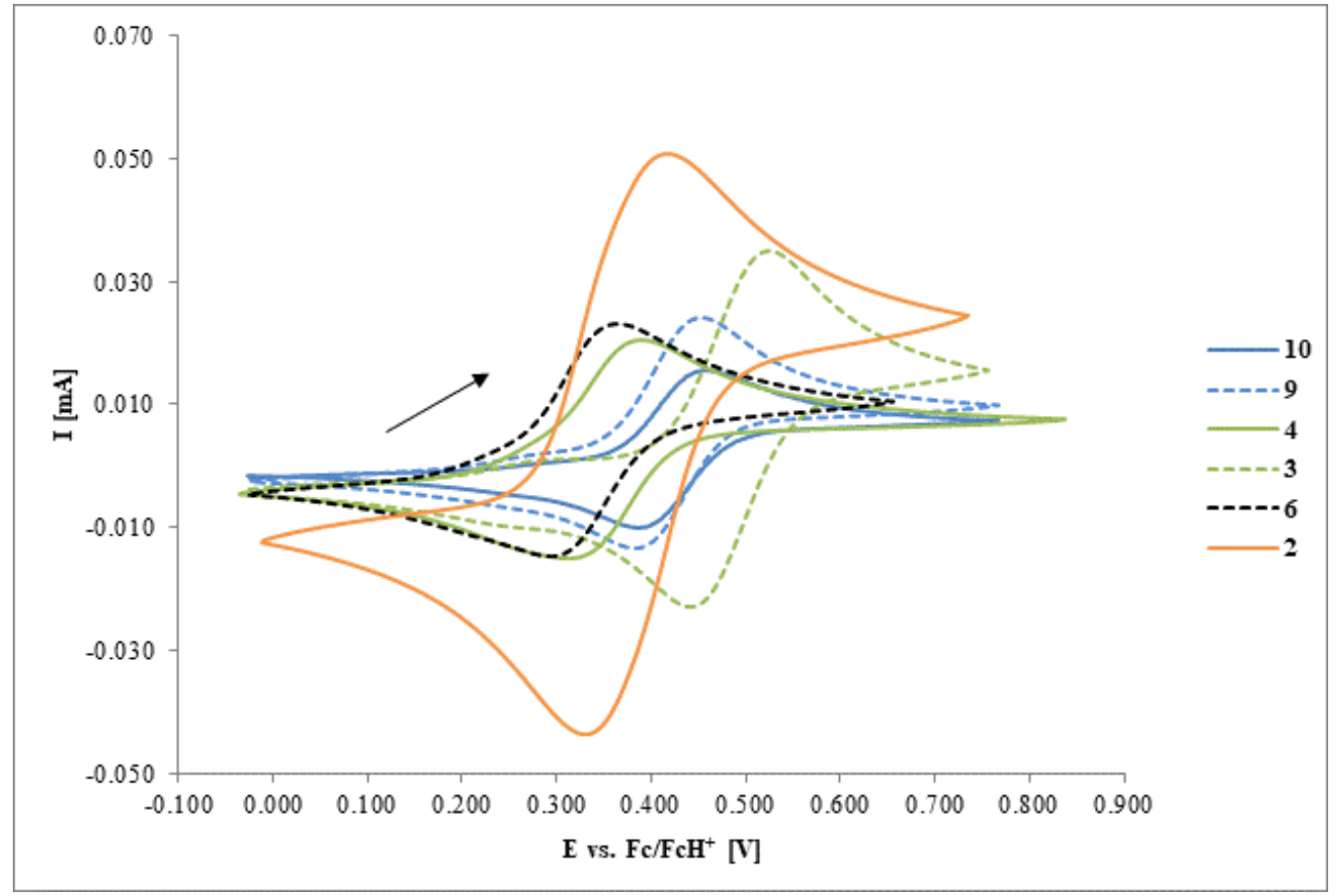

Slika 5 - Ciklički voltamogrami spojeva 2, 3, 4, 6, 9 i 10 s promjenom potencijala od $100 \mathrm{mV} \mathrm{s}^{-1}$ i označenim smjerom promjene Fig. 5 - Cyclic voltammograms of compounds 2, 3, 4, 6, 9, and 10 with scan rate $100 \mathrm{mV} \mathrm{s}^{-1}$ and arrow indicating the scan direction 


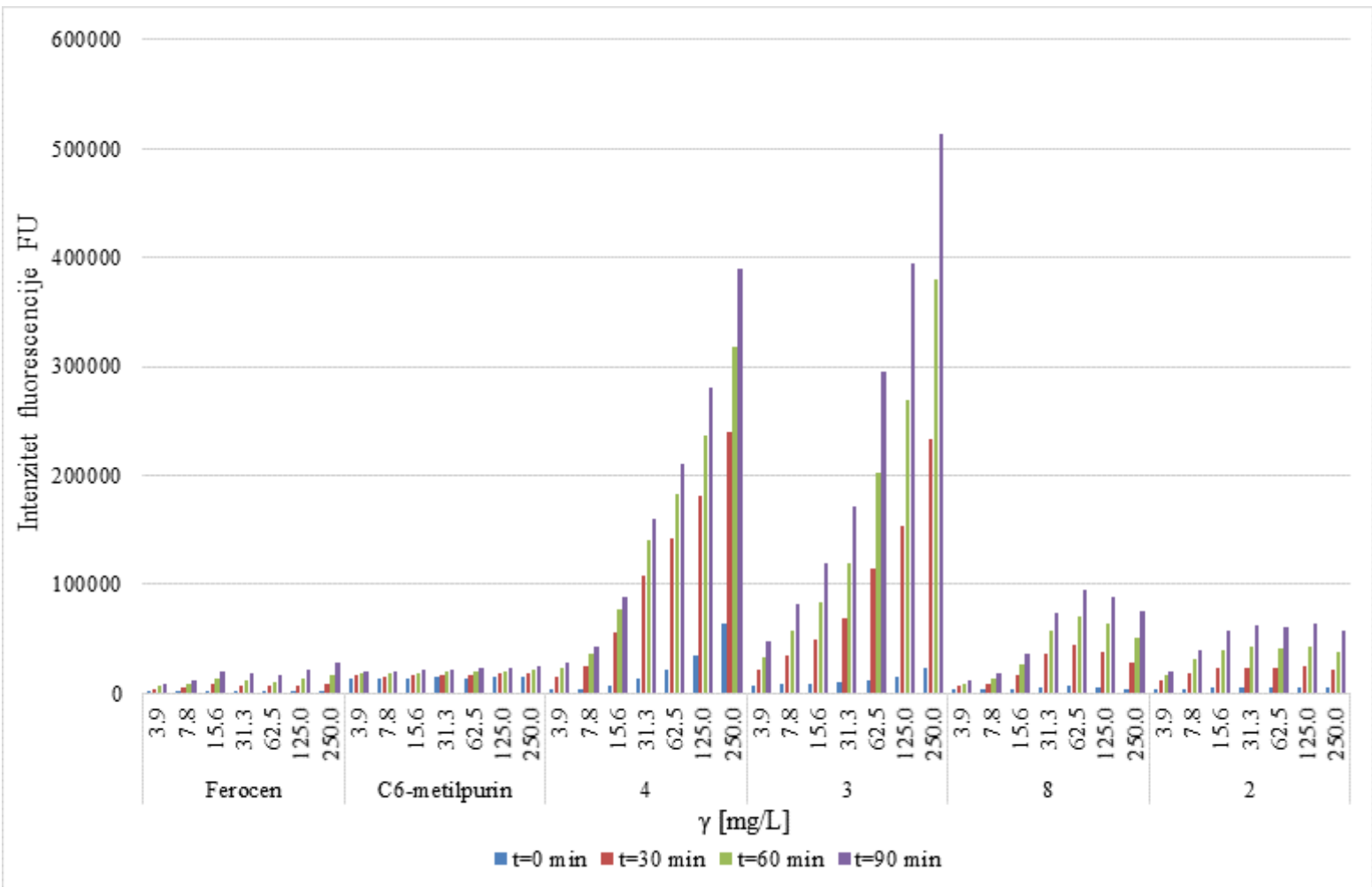

Slika 6 - Izmjerena ekstracelularna ROS aktivnost derivata 2, 3, 4, 8, ferocena i 6-metilpurina spektrofotometrijski pomoću DCFH ${ }_{2}$ DA. Porast intenziteta fluorescencije s povećanjem koncentracije analita i s vremenom.

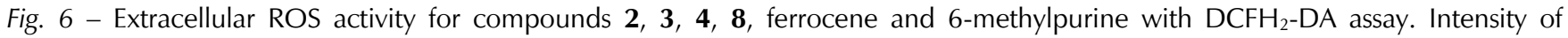
fluorescence increases with concentration of analysed substance as well as with time.

Iz dobivenih je rezultata vidljivo da intenzitet fluorescencije raste $\mathrm{s}$ vremenom i maksimalan je $\mathrm{u}$ vremenu $t=90 \mathrm{~min}$, a raste i s povećanjem koncentracije analita. Značajan porast intenziteta fluorescencije indicira nastanak ROS vrsta, dok vrlo malen porast u fluorescenciji označava sporedne procese koji nisu posljedica nastanka radikala. ROS aktivnost ferocenskih derivata nukleobaza ovisi o C6-purinskom supstituentu i vrsti $\mathrm{N}$-regioizomera pa je vidljivo da C6-arilsupstituirani derivati $(\mathbf{2}, \mathbf{8})$ znatno manje generiraju ROS od alkil-supstituiranih $(\mathbf{3}, \mathbf{4})$. Isto tako, N7 ferocenski derivat metilpurina (3) pokazuje veću ROS aktivnost od N9 izomera (4). Zanimljivo, niti sam ferocen ni nukleobaze $\left(\mathrm{C}_{-} \mathrm{CH}_{3}\right)$ ne pokazuju dobru aktivnost stvaranja ROS vrsta, dok ferocenski kopulat nukleobaze pokazuje dobru ROS aktivnost.

\section{Zaključak}

U okviru istraživanja organometalnih derivata purina, pripravljeni su ferocenski derivati purina i 6merkaptopurina. Dvostupanjskom reakcijom između nukleobaze i ferocenoil-klorida provedeno je aciliranje purinskih baza. $U$ seriji spojeva 1-10 ispitana su redoks-svojstva metodom cikličke voltametrije te acelularna ROS aktivnost spektromefotometrijskom metodom s $\mathrm{DCFH}_{2}$-DA. Ispitani konjugati pokazuju jednoelektronsku reverzibilnu oksidaciju i teže se oksidiraju od ferocena. Također, ispitivani kopulati su bolji oksidansi od ferocena, a N7 izomeri bolji su oksidansi od $\mathrm{N} 9$ izomera. S druge strane, acelularno stvaranje ROS vrsta pokazuje dobru korelaciju s redoks-potencijalima budući da N7 derivati pokazuju veću aktivnost od N9 derivata. Dobra ROS aktivnost spojeva ukazuje na dobru biološku aktivnost ispitanih derivata kao potencijalnih citotoksičnih agenasa za tumorske stanične linije.

\section{ZAHVALA}

Ovaj rad financira Hrvatska zaklada za znanost projektom IP-2016-06-1137. Autori se zahvaljuju Senki Djaković i Jasmini Lapić sa Sveučilišta u Zagrebu, Prehrambenobiotehnološkog fakulteta, istraživačkoj skupini Heinricha Langa s Tehničkog sveučilišta u Chemnitzu, Njemačka, te istraživačkoj skupini Ivane Vinković Vrček s Instituta za medicinska istraživanja i medicinu rada u Zagrebu. 


\section{Popis kratica i simbola}

\section{List of abbreviations and symbols}

\begin{tabular}{|c|c|}
\hline ROS & $\begin{array}{l}\text { - reaktivne kisikove vrste } \\
\text { - reactive oxygen species }\end{array}$ \\
\hline $\mathrm{DCFH}_{2}$-D & $\begin{array}{l}\text { A- 2,7-diklordihidrofluorescein } \\
\text { - 2,7-dichlorodihydrofluorescein }\end{array}$ \\
\hline OrDeN-i & $\begin{array}{l}\text { - orgenometalni derivati nukleobaza } \\
\text { - organometallic nucleobase derivatives }\end{array}$ \\
\hline DNA & $\begin{array}{l}\text { - deoksiribonukleinska kiselina } \\
\text { - deoxyribonucleic acid }\end{array}$ \\
\hline RNA & $\begin{array}{l}\text { - ribonukleinska kiselina } \\
\text { - ribonucleic acid }\end{array}$ \\
\hline $\mathrm{ER} \alpha+$ & $\begin{array}{l}\text { - alfa pozitivni estrogen-receptor } \\
\text { - alpha positive estrogen receptor }\end{array}$ \\
\hline MCF-7 & $\begin{array}{l}\text { - stanična linija tumora dojke } \\
\text { - breast cancer cell line }\end{array}$ \\
\hline $\mathrm{IC}_{50}$ & $\begin{array}{l}\text { - inhibitorna koncentracija } \\
\text { - inhibitory concentration }\end{array}$ \\
\hline $\mathrm{DMSO}_{-} \mathrm{d}_{6}$ & $\begin{array}{l}\text { - deuterirani dimetilsulfoksid } \\
\text { - deuterated-dimethylsulphoxide }\end{array}$ \\
\hline $\mathrm{CDCl}_{3}$ & $\begin{array}{l}\text { - deuterirani kloroform } \\
\text { - deuterated-chloroform }\end{array}$ \\
\hline NMR & $\begin{array}{l}\text { - nuklearna magnetska rezonancija } \\
\text { - nuclear magnetic resonance }\end{array}$ \\
\hline FT-IR & $\begin{array}{l}\text { - Infracrvena spektroskopija } \\
\text { s Fourierovom transformacijom } \\
\text { - Fourier transformation infrared spectroscop }\end{array}$ \\
\hline DMF & $\begin{array}{l}\text { - dimetilformamid } \\
\text { - dimethylformamide }\end{array}$ \\
\hline $\mathrm{CV}$ & $\begin{array}{l}\text { - ciklička voltametrija } \\
\text { - cyclic voltammetry }\end{array}$ \\
\hline SWV & $\begin{array}{l}\text { - voltametrija s pravokutnim } \\
\text { izmjeničnim signalom pobude }\end{array}$ \\
\hline & - square wave voltammetry \\
\hline
\end{tabular}

\section{Literatura \\ References}

1. K. Kowalski, Ferrocenyl-nucleobase complexes: Synthesis, chemistry and application, Coord. Chem. Rev. 317 (2016) 132-156, doi: https://doi.org/10.1016/j.ccr.2016.02.008.

2. K. Heinze, H. Lang, Ferrocene - Beauty and Function, Organometallics, $32 \quad$ (2013) 5623-5625, doi: https://doi.org/10.1021/om400962w.

3. A. Singh, I. Lumb, V. Mehra, V. Kumar, Ferrocene-Appended Pharmacophores: An exciting approach for modulating biological potential of organic scaffolds, Dalton Trans. 48 (2019) 2840-2860, https://doi.org/10.1039/C8DT03440K.
4. S. Realista, S. Quintal, P. N. Martinho, A. I. Melato, A. Gil, T. Esteves, M. de Deus Carvalho, L. P. Ferreira, P. D. Vaz, M. J. Calhorda, Electrochemical studies and potential anticancer activity in ferrocene derivatives, J. Coord. Chem. 70 (2016) 314-327, doi: https://doi.org/10.1080/00958972.2016.1257125.

5. M. Patra, G. Gasser, The medicinal chemistry of ferrocene and its derivatives. Nat. Rev. Chem. 1 (2017) 1-10, doi: https://doi.org/10.1038/s41570-017-0066.

6. A. N. Patwa, S. Gupta, R. G. Gonnade, V. A. Kumar, M. M. Bhadbhade and K. N. Ganesh, Ferrocene-linked thymine/uracil conjugates: Base pairing directed selfassembly and supramolecular packing, J. Org. Chem. 73 (2008) 1508-1515, doi: https://doi.org/10.1021/jo7023416.

7. C. Y. Acevedo-Morantes, E. Melendez, S. P. Singh, J. E. Ramirez-Vick, Cytotoxicity and Reactive Oxygen Species Generated by Ferrocenium and Ferrocene on MCF7 and MCF10A Cell Lines, J. Cancer Sci. Ther. 4 (2012) 271-275, doi: https://doi.org/10.4172/1948-5956.1000154.

8. C. Biot, F. Nosten, L. Fraisse, D. Ter-Minassian, J. Khalife, D. Dive, The antimalarial ferroquine: from bench to clinic, Parasite 3 (2011) 207-214, doi: https://doi.org/10.1051/parasite/2011183207.

9. A. Kondratskyi, K. Kondratska, F. Vanden Abeele, D. Gordienko, C. Dubois, R.-A. Toillon, C. Slomianny, S. Lemière, P. Delcourt, E. Dewailly, R. Skryma, C. Biot, N. Prevarskaya, Ferroquine, the next generation antimalarial drug, has antitumor activity, Sci. Rep. 7 (2017) 15896, doi: 10.1038/s41598-017-16154-2.

10. G. Jaouen, A. Vessieres, S. Top, Ferrocifen type anti cancer drugs, Chem. Soc. Rev. 24 (2015) 8802-8817, doi: https://doi.org/10.1039/C5CS00486A.

11. J. Keiser, M.Vargas, R.Rubbiani, G. Gasser, C. Biot, In vitro and in vivo antischistosomal activity of ferroquine derivatives, Parasit. Vectors, 7 (2014) 424, doi: https://doi.org/10.1186/1756-3305-7-424.

12. J. Shelton, X. Lu, J. A. Hollenbaugh,J. H. Cho, F. Amblard, R. F. Schinazi, Metabolism, biochemical actions, and chemical synthesis of anticancer nucleosides, nucleotides, and base analogs, Chem. Rev. 116 (2016) 14379-14455, doi: https://doi.org/10.1021/acs.chemrev.6b00209.

13. A. A. Simenel, E. A. Morozova, L. V. Snegur, S. I. Zykova, V. V. Kachala, L. A. Ostrovskaya, N. V. Bluchterova, M. M. Fomina, Simple route to ferrocenylalkyl nucleobases. Antitumor activity in vivo. Appl. Organometal. Chem. 23 (2009) 219224, doi: https://doi.org/10.1002/aoc.1500.

14. K. Kowalski, J. Skiba, L. Oehninger, I. Ott, J. Solecka, A. Rajnisz, B. Therrien, Metallocene-Modified Uracils: Synthesis, Structure, and Biological Activity, Organometallics 32 (2013) 5766-5773, doi: https://doi.org/10.1021/om400294s.

15. H. V. Nguyen, A. Sallustrau, J. Balzarini, M. R. Bedford, J. C. Eden, N. Georgousi, N. J. Hodges, J. Kedge, Y. Mehellou, C. Tselepis, J. H. R. Tucker, Organometallic Nucleoside Analogues with Ferrocenyl Linker Groups: Synthesis and Cancer Cell Line Studies, J. Med. Chem. 57 (2014) 58175822, doi: https://doi.org/10.1021/jm500246h.

16. J. Skiba, R. Karpowicz, I. Szabo, B. Therrien, K. Kowalski, Synthesis and anticancer activity studies of ferrocenylthymine-3,6-dihydro-2H-thiopyranes - A new class of metallocene-nucleobase derivatives, J. Organomet. Chem. 794 (2015) 216-222, doi: https://doi.org/10.1016/j.jorganchem.2015.07.012. 
17. K. Kowalski, Ł. Szczupak, S. Saloman, D. Steverding, A. Jabłoński, V. Vrček, A. Hildebrandt, H. Lang, A. RybarczykPirek, Cymantrene, Cyrhetrene and Ferrocene Nucleobase Conjugates: Synthesis, Structure, Computational Study, Electrochemistry and Antitrypanosomal Activity, ChemPlusChem, $82 \quad$ (2016) 303, doi: https://doi.org/10.1002/cplu.201600462.

18. M. K. Ismail, K. A. Armstrong, S. L. Hodder, S. L. Horswell, L. Male, H. V. Nguyen, E. A. Wilkinson, N. J. Hodges, J. H. R. Tucker, Organometallic Nucleoside Analogues: Effect of the Metallocene Metal Atom on Cancer Cell Line Toxicity, Dalton Trans. 49 (2020) 1181-1190, doi: https://doi.org/10.1039/C9DT04174E.

19. J. Lapić, V. Havaić, D. Šakić, K. Sanković, S. Djaković, V. Vrček, Ferrocenoyl-Substituted Pyrimidine Nucleobases: An Experimental and Computational study of Regioselective Acylation of Uracil, Thymine, and 5-Fluorouracil, Eur. J. Org. Chem. (2015) 5424-5431, doi: https://doi.org/10.1002/ejoc.201500647.

20. M. Toma, L. Božičević, J. Lapić, S. Djaković, D. Šakić, T. Tandarić, R. Vianello, V. Vrček, Transacylation in FerrocenoylPurines. NMR and Computational Study of the Isomerization Mechanism, J. Org. Chem. 84 (2019) 12471-12480, doi: https://doi.org/10.1021/acs.joc.9b01944.

21. A. Hildebrandt, K. Al Khalyfeh, D. Schaarschmidt, M. Korb, Multi-functionalized ferrocenes: Synthesis and characterization, J. Organomet. Chem. 804 (2016) 87-94, doi: https://doi.org/10.1016/j.jorganchem.2015.12.027.

22. R. Brandt, A.S. Keston, Synthesis of diacetyldichlorofluorescin: A stable reagent for fluorometric analysis,
Anal. Biochem. 11 (1965) 6-9, doi: https://doi.org/10.1016/0003-2697(65)90035-7.

23. A. S. Keston, R. Brandt, The fluorometric analysis of ultramicro quantities of hydrogen peroxide, Anal. Biochem. 11 (1965) 1-5, doi: https://doi.org/10.1016/0003-2697(65)90034-5.

24. M. Zhong, M. J. Robins, Regiospecific N9 Alkylation of 6(Heteroaryl)purines: Shielding of N7 by a Proximal Heteroaryl C-H1, J. Org. Chem. 71 (2006) 8901-8906, doi: https://doi.org/10.1021/jo061759h.

25. M. Koch, Doktorska disertacija, Novel antagonists for the human adenosine $\mathrm{A} 2 \mathrm{~A}$ and $\mathrm{A} 3$ receptor via purine nitration: synthesis, 2011., str. 42.

26. T. Pospieszny, E. Wyrzykiewicz, A practical synthesis of new S,N-disubstituted derivatives of 5-(4methylpiperidino)methyl-2-thiouracil, Tetrahedron Lett. 49 (2008) 5319-5321, doi: https://doi.org/10.1016/j.tetlet.2008.06.079.

27. V. Havaić, S. Djaković, J. Lapić, T. Weitner, D. Šakić, V. Vrček, Reduction Potential of Ferrocenoyl-Substituted Nucleobases. Experimental and Computational Study, Croat. Chem. Acta 90 (2017), doi: https://doi.org/10.5562/cca3229.

28. A. Houlton, C. J. Isaac, A. E. Gibson, B. R. Horrocks, Synthesis, structure and redox properties of ferrocenylmethyl nucleobases, J. Chem. Soc. Dalton Trans. (1999) 3229-3234, doi: https://doi.org/10.1039/A905168F.

29. A. K. Pal, D. Bello, B. Budhlall, E. Rogers, Screening for oxidative stress elicited by engineered nanomaterials: Evaluation of acellular DCFH assay, Dose-Response, 10 (2012) 308-330, doi: https://doi.org/10.2203/doseresponse.10-036.Pal.

\section{SUMMARY}

\section{Redox Properties of Ferrocene-substituted Nucleobases}

\section{Mateja Toma* and Valerije Vrček}

A series of ferrocene-substituted purine-nucleobase derivatives 1-10 were synthesized and their redox potential was measured by cyclic voltammetry. Measured compounds showed a reversible one-electron oxidation in the range of 330-470 mV. A difference of $100 \mathrm{mV}$ between N7 and N9 regioisomers was observed. In order to examine the tendency of ferrocene-nucleobase conjugates to produce reactive oxygen species (ROS), an acellular screening with $\mathrm{DCFH}_{2}$-DA assay was carried out. The nucleobases coupled with ferrocene generated ROS, while neither ferrocene itself nor the nucleobases were active. Changing the substituents on the purine ring can significantly influence the ROS generation of ferrocene-substituted nucleobases, which support design of biologically active ferrocene-nucleobase conjugates.

\section{Keywords}

Ferrocene-substituted purine-nucleobase, redox potential, reactive oxygen species (ROS)

University of Zagreb

Faculty of Pharmacy and Biochemistry

Ante Kovačića 1

10000 Zagreb, Croatia
Original scientific paper

Received April 21, 2020

Accepted June 24, 2020 